We have thoroughly enjoyed working on this project and would love to share the results and more about how we secured funding for this project through the HLF.

We have an audio post with a snapshot of some of the recordings. The display is portable as we intend to move it around our community over the coming months.

\section{P-24 SIMPLE ACTS OF KINDNESS: RESPECTFUL BURIALS FOR NEEDY MUSLIMS WITHIN A HOLISTIC END OF LIFE SERVICE}

Abu Mumin, Caroline Mawer, Ahad Miah. Edencare UK, London, UK

\subsection{6/bmispcare-2016-001245.48}

Background Although the specific end-of-life needs of Black and Asian people have been discussed in some detail, relatively few Muslim communities have been involved in developing end-oflife services. Important religious imperatives for Muslims include not only having a funeral as soon as possible, but also avoiding cremation. Although it is customary for Muslim communities to spontaneously help with burial costs for the needy, there is increasing funeral poverty across the UK. Since burials are even more expensive than cremations, there are significant practical and financial pressures on dying Muslims and their families. Muslim community members in East London have therefore developed a Muslim Burial Fund.

Aims To ensure that needy Muslims are helped with the practicalities and financial costs of a respectful Muslim burial, as part of a holistic end of life service.

Methods The Muslim Burial Fund has responded to the specific requirements of needy dying or deceased individuals. Services offered have included: hospital and home visits; help with statutory declarations; help with Social Fund applications; helping fund, organise and attend funerals and burials; funeral prayers; and supporting family and friends. If necessary, a Rapid Response Team carries out 24/7 visits when a person is nearing death.

Results So far, 18 Muslims have been given free and personalised burial support. The initial focus has been on the neediest: those with no next of kin; those who have no Muslim family; and Muslims found dead by the police.

With increased experience and knowledge, the aim is to sustainably expand the service.

Conclusions The Burial Fund provides a simple act of kindness. By breaking the community taboo around discussing death, the service also promotes engagement with a local Muslim befriending and advocacy service for those nearing end-of-life.

\section{P-25 VOLUNTEERS: RESOURCES OR PEOPLE?}

Sally Muylders. St Joseph's Hospice, London, UK

10.1136/bmjspcare-2016-001245.49

The hospice movement has been built on the efforts of volunteers and their contributions continue to be essential for the survival of the movement today. The impact of the work volunteers undertake is often quantified in terms of benefit to the hospice in financial terms or in additional services provided to patients, but the impact on the volunteer themselves and on the wider community is often overlooked. This is an essential component of a community development or compassionate communities approach. This presentation will assume a new perspective and argue that a volunteer-focused perspective is essential in developing a community development approach in a hospice, but that this often sits at odds with a predominant patient-focused view.

Compassionate Neighbours is a community development project run through a large hospice which aims to start a social movement to transform the experiences of those affected by death, dying and loss. A key component of this is the training of community members to become 'compassionate neighbours' and visit people locally in need. The project manager is responsible for recruiting, selecting, training and supervising the compassionate neighbours and managing their position within the hospice. The manager does not see them just as a resource for the hospice to use but rather sees their personal development, their relationship with the hospice and their understanding of its work as key outcomes in their own right.

This presentation will use a case study approach to explore this situation in more detail, making use of evidence from the project evaluation to explore issues of risk, autonomy and the difficulties of starting community development projects where the outcomes are difficult to specify in advance. The outcomes of this approach including a buddying system, community champions and the acceptance of the project in the wider community will be presented.

\section{P-26 WELCOME TO THE MILL, ST CATHERINE'S PARK}

Lynn Kelly. St Catherine's Hospice, Preston, UK

\subsection{6/bmjspcare-2016-001245.50}

Background The Mill, St Catherine's Park is to help address the feelings of apprehension and abandonment many patients feel about 'entering' palliative care or when they are discharged. Prior to The Mill opening, 96\% of hospice patients, staff and volunteers surveyed felt that an informal and welcoming drop-in centre could help to overcome this. In November 2014 The Mill, St Catherine's Park opened - a community hub with a welcoming cafe on the ground floor and therapy rooms on the first floor.

Aims

- To promote independence through specialised information, advice, counselling, therapies and peer support in a relaxing, therapeutic environment

- To provide continuity of care to reduce apprehension and isolation

- To engage with the local community and change public perception of hospice care.

\section{Method}

- Use of volunteer 'advisors' to provide help, support and information to people to encourage independence and choice.

- New patient education programmes to encourage independence and choice

- A new drop-in coffee morning for patients to overcome loneliness, anxiety and feelings of abandonment.

- A timetable of gentle exercise activities such as a tai chi and yoga.

Results

- Creation of an informal, non-clinical environment for patients and families - 'it was so good to have somewhere in the grounds to go for some rest and relaxation; thank you so much for the haven you offered at this time' 